\title{
PENINGKATAN KOMPETENSI GURU DALAM MERANCANG RPP MELALUI BIMBINGAN BERKALA DI SMPN 3 KECAMATAN LAREH SAGO HALABAN SEMESTER 1 TP. 2019/2020
}

\author{
Harnieti
}

Email : harnieti06@gmail.com

\begin{abstract}
This article aims to reveal about increasing teacher competence in designing lesson plans through the use of periodic guidance methods at SMPN 3, Lareh Sago Halaban District, Semester 1 TP. 2019/2020.

The research subjects were teachers who had not been able to design good and quality lesson plans, with a total of 5 people, namely 1 male and 4 female. This research was a School Action Research which was conducted in 3 cycles, and each cycle was carried out for 3 meetings. The data collection technique was carried out by direct observation and accompanied by peers as observers using observation sheets, field journals and lesson plan assessment instruments. Then the results of the observations was analyzed by looking at the improvement in each cycle. In cycle 1, the average competence of teachers in designing lesson plans was 67, $27 \%$. In Cycle 2 it increased to $76.97 \%$. The results of this study indicate that there is an increase in teacher competence in designing lesson plans from cycle 1 to cycle 2 of $9.7 \%$.

While the competence of teachers in designing lesson plans from cycle 2 to cycle 3 , there was also an increase. In cycle 2 the competence of teachers in designing lesson plans was 76, 97\%, while in cycle 3 it was 88, 48\%. Then there was an increase of about $11.22 \%$. Based on the results of this study, it can be concluded that the application of the periodic guidance method can improve teacher competence in designing lesson plans at SMPN 3, Lareh Sago Halaban District, semester 1 TP. 2019/2020.
\end{abstract}

Keywords: Competence, lesson plans, periodic guidance

\begin{abstract}
ABSTRAK
Artikel ini bertujuan untuk mengungkapkan tentang peningkatan kompetensi guru dalam merancang RPP melalui penggunaan metode bimbingan berkala di SMPN 3 Kecamatan Lareh Sago Halaban Semester 1 TP. 2019/2020.

Subjek penelitian adalah guru-guru yang belum mampu merancang RPP yang baik dan berkualitas, dengan jumlah 5 orang, yaitu laki-laki sebanyak 1 orang dan perempuan 4 orang. Penelitian ini merupakan Penelitian Tindakan Sekolah yang dilaksanakan sebanyak 3 siklus, dan masing-masing siklus dilaksanakan selama 3 kali pertemuan. Teknik pengumpulan data dilakukan dengan observasi langsung dan didampingi oleh teman sejawat sebagai observer dengan menggunakan lembar observasi, jurnal lapangan dan instrument penilaian RPP. Kemudian hasil pengamatan akan dianalisis dengan melihat peningkatannya dalam setiap siklus. Pada siklus 1 rata-rata kompetensi guru merancang RPP sebesar 67, 27\%. Pada Siklus 2 meningkat menjadi 76,97\%. Hasil penelitian ini menunjukkan bahwa terjadi peningkatan kompetensi guru dalam merancang RPP dari siklus 1 ke siklus 2 sebesar 9,7\%. Sementara kompetensi guru merancang RPP dari siklus 2 ke siklus
\end{abstract}


3, juga terjadi peningkatan. Pada siklus 2 kompetensi guru merancang RPP sebesar 76, 97\%, sementara pada siklus 3 menjadi 88, 48\%. Maka terjadi penigkatan sekitar 11,22\%. Berdasarkan hasil penelitian tersebut, dapat disimpulkan bahwa penerapan metode bimbingan berkala dapat meningkatkan kompetensi guru dalam merancang RPP di SMPN 3 Kecamatan Lareh Sago Halaban semester 1 TP. 2019/2020.

Kata Kunci: Kompetensi, RPP, Bimbingan berkala

\section{PENDAHULUAN}

Permendikbud Nomor 22 Tahun 2016 tentang Standar Proses menyatakan bahwa standar proses untuk satuan pendidikan dasar dan menengah mencakup perencanaan proses pembelajaran, pelaksanaan proses pembelajaran, penilaian hasil pembelajaran, dan pengawasan proses pembelajaran. Standar proses ini mengandung makna bahwa proses pembelajaran perlu direncanakan, dilaksanakan, dinilai, dan diawasi agar terlaksana secara efektif dan efisien.

Berpijak pada standar proses di atas bahwa seorang pendidik sebelum melakukan pembimbingan proses pembelajaran di depan kelas, terlebih dahulu melakukan perencanaan dengan serangkaian perangkat pembelajaran sesuai dengan mata pelajaran yang diampu dalam rangka acuan sewaktu menyajikan pembelajaran. Perangkat pembelajaran tersebut terdiri dari silabus, penetapan KKM, pemetaan materi, program penilaian, program semester, program tahunan, bahan ajar dan RPP.

Fenomena yang ada di lapangan, masih banyak guru yang belum membuat perangkat pembelajaran dengan semestinya, sebagian besar belum mampu menyusun perangkat pembelajaran yang aplikatif, berdaya guna dan berhasil guna serta menggunakan perangkat pembelajaran yang dibuatnya untuk pelaksanaan pembelajaran yang aktif, inovatif, kreatif, efektif dan menyenangkan (Paikem).

Berbagai riset menunjukan bahwa kebanyakan guru di Indonesia masih mengajar menggunakan pendekatan tradisional yang memosisikan siswa sebagai objek pasif di dalam pembelajaran. Fenomena yang ada di lapangan juga membuktikan bahwa sebagian besar guru-guru dalam merumuskan pembelajaran masih mengadopsi rencana pembelajaran yang sudah ada. Tidak ada inisiatif guru untuk merumuskan dan mencoba menemukan metode atau langkah-langkah pembelajaran sendiri yang sesuai dengan kondisi siswa di kelasnya.

Salah satu dampaknya adalah rendahnya kualiats RPP yang dihasilkan oleh guru. Hal ini akan berpengaruh terhadap rendahnya kualitas pembelajaran.Walaupun telah banyak upaya yang peneliti lakukan seperti melengkapi buku-buku sumber, menyediakan sarana pembelajaran, mengirim guru mengikuti kegiatan MGMP, seminar, diklat dan sebagainya, namun ternyata masih terdapat guru yang kesulitan dalam merancang RPP.

Mengatasi permasalahan di atas peneliti merasa perlu mencari solusi agar terjadi peningkatan kompetensi guru dalam merancang RPP. Strategi yang diduga mampu mencapai hal tersebut adalah dengan menerapkan metode bimbingan berkala.

Nana Syaodih Sukmadinata (2006: 62) menyatakan bahwa metode pembelajaran/pembimbingan terhadap seseorang atau kelompok kecil yang terdiri dari maksimal empat sampai 5 orang dan didampingi langsung oleh kepala sekolah/ fasilitator. Hal ini dapat dilakukan selama beberapa hari, sesuai dengan 
maksud dan tujuan, isi, proses dan kegiatan yang telah ditentukan sebelumnya oleh kepala sekolah/fasilitator.

Peneliti meyakini bahwa penerapan metode bimbingan yang melibatkan peran aktif guru dalam kegiatan dapat meningkatkan kompetensinya. Metode bimbingan berkala lebih memperhatikan kepada aspek yang menyebabkan permasalahan bagi guru, kemudian diberikan solusi yang lebih mengarah kepada tutor teman sejawat. Hal ini jelas akan menimbulkan motivasi, aktivitas dan sikap kooperatif selama kegiatan berlangsung, sehingga hasil kerja guru lebih berkualitas.

Oleh sebab itu penulis tertarik untuk melakukan penelitian tindakan sekolah dengan judul: "Peningkatan Kompetensi Guru dalam Merancang RPP Melalui Bimbingan Berkala di SMPN 3 Kecamatan Lareh Sago Halaban Semester 1 TP. 2019/2020".

\section{METODOLOGI}

Penelitian Tindakan Sekolah (PTS) ini dilaksanakan di SMPN 3 Kecamatan Lareh Sago Halaban pada Semester 1 TP. 2019/2020, yaitu pada bulan Juli sampai dengan September 2019.

Subjek penelitian adalah guru SMPN 3 Kecamatan Lareh Sago Halaban yang mengalami kesulitan dalam merancamg RPP, berjumlah 5 orang, yaitu lakilaki berjumlah 1 orang dan perempuan sebanyak 4 orang. Metode yang digunakan adalah bimbingan berkala.

Adapun teknik pengumpulan data dilakukan dengan observasi langsung dan didampingi oleh teman sejawat sebagai observer dengan menggunakan lembar observasi. Kemudian hasil pengamatan akan dianalisis dengan melihat peningkatannya dalam setiap siklus, dengan menggunakan catatan lapangan, lembar observasi dan instrument penilaian RPP.

Data pengisian lembar observasi kegiatan guru dalam merancang RPP akan dianalisis dengan cara kuantitatif dalam bentuk persen. Untuk melihat persentase peningkatan kompetensi guru dalam merancang RPP untuk masingmasing indikator dengan ketentuan sebagai berikut:

$\mathrm{P}=\underline{\mathrm{F}} \times 100 \%$

\section{Keterangan}

$\mathrm{P}=$ Angka Persentase Peningkatan Kompetensi

$\mathrm{F}=$ Skor perolehan

$\mathrm{N}=$ Skor Maksimal

\section{HASIL PENELITIAN DAN PEMBAHASAN}

\section{A. Hasil Penelitian}

Hasil pengamatan terhadap perilaku positif guru dalam merancang RPP selama pelaksanaan kegiatan pada siklus I dan II mengalami Peningkatan sebagai berikut: 
Tabel 5: Perbandingan Kompetensi guru dalam merancang RPP antara siklus I dengan siklus II

\begin{tabular}{|c|c|c|c|c|c|}
\hline \multirow[b]{2}{*}{ No } & \multirow[b]{2}{*}{ Aspek yang diteliti } & \multicolumn{2}{|l|}{ Siklus } & \multicolumn{2}{|c|}{ Keterangan } \\
\hline & & I (\%) & II $(\%)$ & $\mathrm{I}$ & II \\
\hline 1 & $\begin{array}{lccc}\text { Guru merancang } & \text { RPP } & \text { berdasarkan } \\
\text { silabus dan panduan BSNP } & \end{array}$ & 73,33 & 80 & $\mathrm{~B}$ & $\mathrm{~B}$ \\
\hline 2 & $\begin{array}{l}\text { Guru memahami dan menguasai } \\
\text { komponen dan sistematika RPP dengan } \\
\text { benar. }\end{array}$ & 86,67 & 93,33 & $\mathrm{AB}$ & $\mathrm{AB}$ \\
\hline 3. & $\begin{array}{l}\text { Guru merumuskan identitas dengan } \\
\text { lengkap }\end{array}$ & 86,67 & 100 & $\mathrm{AB}$ & $\mathrm{AB}$ \\
\hline 4. & $\begin{array}{l}\text { Guru mencantumkan alokasi waktu yang } \\
\text { yang sesuai }\end{array}$ & 86,67 & 100 & $\mathrm{AB}$ & $\mathrm{AB}$ \\
\hline 5. & $\begin{array}{l}\text { Guru merumuskan tujuan pada RPP } \\
\text { berdasarkan indikator yang ada pada } \\
\text { silabus. dan memuat ABCD }\end{array}$ & 46,67 & 66,67 & $\mathrm{~K}$ & $\mathrm{C}$ \\
\hline 6. & $\begin{array}{l}\text { Guru merumuskan materi ajar } \\
\text { berdasarkan marei reguler, remidial dan } \\
\text { pengayaaan }\end{array}$ & 40 & 46,67 & $\mathrm{~K}$ & $\mathrm{~K}$ \\
\hline 7. & $\begin{array}{l}\text { Guru memilih metode dan model } \\
\text { pembelajaran yang tepat dan relevan }\end{array}$ & 53,33 & 60 & $\mathrm{~K}$ & $\mathrm{~K}$ \\
\hline 8. & $\begin{array}{l}\text { Guru merumuskan langkah kegiatan } \\
\text { pembelajaran sesuai dengan struktur } \\
\text { yang lazim (kegiatan pendahuluan, } \\
\text { kegiatan inti, kegiatan akhir)serta } \\
\text { mengambarkan sintak } \\
\text { pembelajaran }\end{array}$ & 53,33 & 60 & $\mathrm{~K}$ & $\mathrm{C}$ \\
\hline 9. & $\begin{array}{l}\text { Guru menetapkan alat, bahan dan sumber } \\
\text { sesuai dengan tujuan atau kompetensi } \\
\text { yang hendak dicapai siswa. }\end{array}$ & 73,33 & 80 & $\mathrm{~B}$ & $\mathrm{~B}$ \\
\hline 10. & $\begin{array}{l}\text { Guru menyusun instrumen atau alat } \\
\text { penilaian sesuai dengan tujuan dan } \\
\text { indikator. }\end{array}$ & 66,67 & 80 & $\mathrm{C}$ & $\mathrm{B}$ \\
\hline 11. & $\begin{array}{l}\text { Guru merumuskan sumber belajar } \\
\text { dengan benar }\end{array}$ & 73,33 & 80 & B & $\mathrm{B}$ \\
\hline \multicolumn{2}{|c|}{ Rata -rata } & 67,27 & 76,97 & $\mathrm{C}$ & B \\
\hline
\end{tabular}

Tabel 6: Rentangan Penilaian

\begin{tabular}{|l|l|}
\hline Nilai Kuantitatif & Keterangan \\
\hline $86-100$ & Amat baik \\
$71-85$ & Baik \\
$56-70$ & Cukup \\
$<56$ & Kurang \\
\hline
\end{tabular}


Tabel 7: Peningkatan Kompetensi Guru Merancang RPP dari Siklus I ke Siklus II

\begin{tabular}{|l|l|l|l|l|}
\hline Siklus & Pertemuan 1 & Pertemuan 2 & Pertemuan 3 & Rata-rata \\
\hline Siklus I & 52,73 & 72,73 & 76,36 & 67,27 \\
\hline Siklus II & 70,91 & 76,36 & 83,64 & 76,97 \\
\hline Peningkatan (\%) & & 9,7 \\
\hline
\end{tabular}

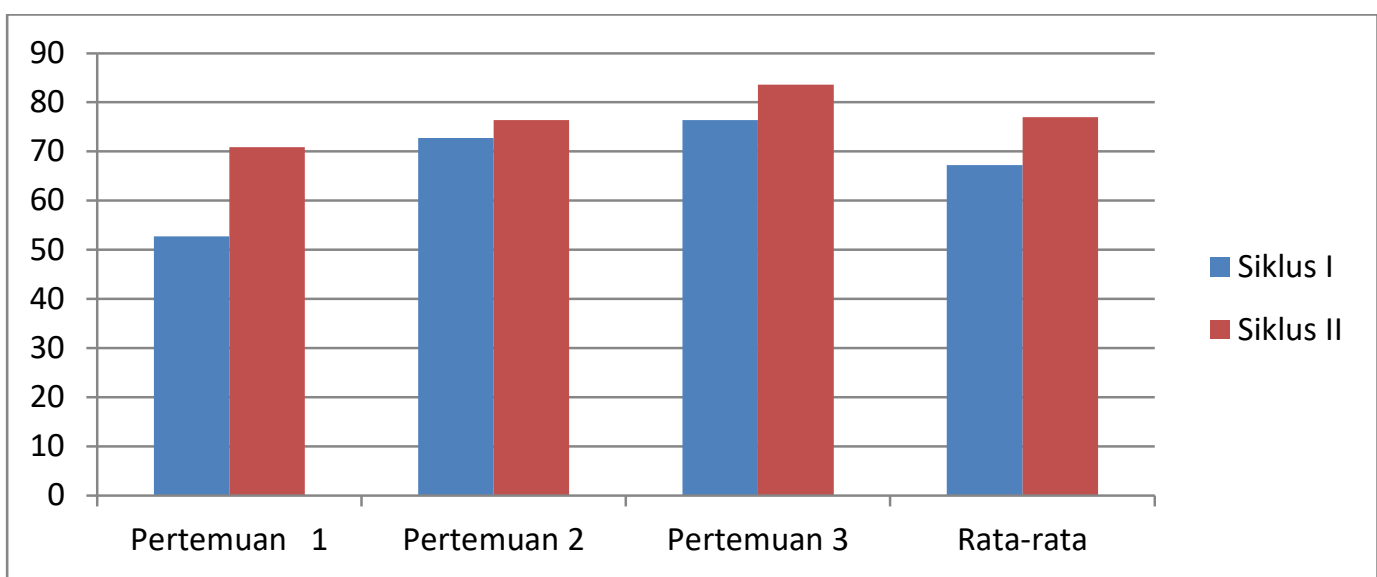

Grafik 1: Perbandingan kompetensi guru dalam merancang RPP antara siklsus 1 dengan siklus II

Kompetensi guru yang terlihat pada Tabel 5 dan grafik 1 di atas sebagai berikut:

1. Merancang RPP berdasarkan silabus dan panduan BSNP mengalami peningkatan dari $73,33 \%$ menjadi $80 \%$, jadi peningkatannya sebesar $6,67 \%$

2. Guru yang memahami dan menguasai komponen RPP dengan benar meningkat dari 86,67\% menjadi 93,33\%, jadi peningkatannya sebesar 6,66\%.

3. Guru merumuskan identitas dengan lengkap, meningkat dari $86,67 \%$ menjadi $100 \%$, jadi meningkat sebesar $13,33 \%$

4. Guru mencantumkan alokasi waktu yang yang sesuai, siklus 1 rata-ratanya sebesar $86,67 \%$ menjadi $100 \%$, jadi meningkat sebesar $13,33 \%$

5. Guru merumuskan tujuan pada RPP berdasarkan indikator yang ada pada silabus. dan memuat ABCD, dari 45,67 meningkat menjadi 66,67, jadi peningkatannya $20 \%$, atau dari prediket K menjadi C

6. Guru merumuskan materi ajar berdasarkan marei reguler, remidial dan pengayaaan, dari $40 \%$ menjadi $46,67 \%$, jadi peningkatannya $6,67 \%$, sementara prediket masih $\mathrm{K}$

7. Guru memilih metode dan model pembelajaran yang tepat dan relevan, dari $53,33 \%$, menjadi $60 \%$, dengan peningkatan sebesar 6,67\%, Prediket dari K menajdi C

8. Guru merumuskan langkah kegiatan pembelajaran sesuai dengan struktur yang lazim (kegiatan pendahuluan, kegiatan inti, kegiatan akhir)serta mengambarkan sintak model pembelajaran, dari 53,33\% menjadi $60 \%$, denganpeningaktan sebesar $6,67 \%$, dari prediket $\mathrm{K}$ ke C

9. Guru menetapkan alat, bahan dan sumber sesuai dengan tujuan atau kompetensi yang hendak dicapai siswa, dari $73,33 \%$ menjadi $80 \%$, terjadi peningkatan sebesar $6,67 \%$ dengan prediket $B$ 
10. Guru menyusun instrumen atau alat penilaian sesuai dengan tujuan dan indikator, dari 66,67 menjadi $80 \%$, dengan peningkatan $13,67 \%$ atau dari pediket $\mathrm{C}$ menajdi $\mathrm{B}$.

11. Guru merumuskan sumber belajar dengan benar. Dari $73,33 \%$ menjadi $80 \%$ dengan peningkatan $6,67 \%$ sementara prediket tetap B

Peningkatan kompetensi guru dalam merancang RPP dari siklus I ke siklus II sebesar 9,7\%. Selanjutnya juga terjadi peningkatan kompetensi guru dalam merancang RPP dari siklus II ke siklus III secara signifikan. Jadi dapat dilihat peningkatannya pada tabel berikut:

Tabel 9: Perbandingan Kompetensi guru dalam merancang RPP Antara Siklus 1I dengan Siklus III

\begin{tabular}{|l|l|l|l|l|l|}
\hline No & Aspek yang diteliti & \multicolumn{2}{l|}{ Siklus } & \multicolumn{2}{l|}{ Keteranga } \\
\cline { 2 - 6 } & $\begin{array}{l}\text { II } \\
(\%)\end{array}$ & $\begin{array}{l}\text { III } \\
(\%)\end{array}$ & II & III \\
\hline 1 & $\begin{array}{l}\text { Guru merancang RPP berdasarkan silabus } \\
\text { dan panduan BSNP }\end{array}$ & 80 & 100 & $\mathrm{~B}$ & $\mathrm{AB}$ \\
\hline 2 & $\begin{array}{l}\text { Guru memahami dan menguasai } \\
\text { komponen dan sistematika RPP dengan } \\
\text { benar. }\end{array}$ & 93,33 & 100 & $\mathrm{AB}$ & $\mathrm{AB}$ \\
\hline 3. & $\begin{array}{l}\text { Guru merumuskan identitas dengan } \\
\text { lengkap }\end{array}$ & 100 & 100 & $\mathrm{AB}$ & $\mathrm{AB}$ \\
\hline 4. & $\begin{array}{l}\text { Guru mencantumkan alokasi waktu yang } \\
\text { yang sesuai }\end{array}$ & 100 & 100 & $\mathrm{AB}$ & $\mathrm{AB}$ \\
\hline 5. & $\begin{array}{l}\text { Guru merumuskan tujuan pada RPP } \\
\text { berdasarkan indikator yang ada pada } \\
\text { silabus. dan memuat ABCD }\end{array}$ & 66,67 & 86,67 & $\mathrm{~B}$ & $\mathrm{AB}$ \\
\hline 6. & $\begin{array}{l}\text { Guru merumuskan materi ajar berdasarkan } \\
\text { marei reguler, remidial dan pengayaaan }\end{array}$ & 46,67 & 73,33 & $\mathrm{~K}$ & $\mathrm{~B}$ \\
\hline 7. & $\begin{array}{l}\text { Guru memilih metode dan model } \\
\text { pembelajaran yang tepat dan relevan }\end{array}$ & 60 & 80 & $\mathrm{~K}$ & $\mathrm{~B}$ \\
\hline 8. & $\begin{array}{l}\text { Guru merumuskan langkah kegiatan } \\
\text { pembelajaran sesuai dengan struktur yang } \\
\text { lazim (kegiatan pendahuluan, kegiatan } \\
\text { inti, kegiatan akhir)serta mengambarkan } \\
\text { sintak model pembelajaran }\end{array}$ & 60 & 73,33 & $\mathrm{~K}$ & $\mathrm{~B}$ \\
\hline 9. & $\begin{array}{l}\text { Guru menetapkan alat, bahan dan sumber } \\
\text { sesuai dengan tujuan atau kompetensi } \\
\text { yang hendak dicapai siswa. }\end{array}$ & 80 & 100 & $\mathrm{~B}$ & $\mathrm{AB}$ \\
\hline 10. & $\begin{array}{l}\text { Guru menyusun instrumen atau alat } \\
\text { penilaian sesuai dengan tujuan dan } \\
\text { indikator. }\end{array}$ & 80 & 80 & $\mathrm{~B}$ & $\mathrm{~B}$ \\
\hline 11. & $\begin{array}{l}\text { Guru merumuskan sumber belajar dengan } \\
\text { benar }\end{array}$ & 80 & 80 & $\mathrm{~B}$ & $\mathrm{~B}$ \\
\hline Rata - rata & 76,36 & 88,48 & $\mathrm{~B}$ & $\mathrm{~B}$ \\
\hline
\end{tabular}


Tabel 10: Rentangan Penilaian

\begin{tabular}{|l|l|}
\hline Nilai Kuantitatif & Keterangan \\
\hline $86-100$ & Amat baik \\
\hline $71-85$ & Baik \\
\hline $56-70$ & Cukup \\
\hline$<56$ & Kurang \\
\hline
\end{tabular}

Tabel 11: Peningkatan Kompetensi Guru dalam Merancang RPP Antara Siklus 1 I dan Siklus III

\begin{tabular}{|l|l|l|l|l|}
\hline Siklus & $\begin{array}{l}\text { Pertemuan } \\
1\end{array}$ & Pertemuan 2 & $\begin{array}{l}\text { Pertemuan } \\
3\end{array}$ & Rata-rata \\
\hline Siklus II & 70,91 & 76,36 & 83,64 & 76,97 \\
\hline Siklus III & 85,45 & 89,09 & 90,91 & 88,48 \\
\hline Peningkatan (\%) & & 11,22 \\
\hline
\end{tabular}

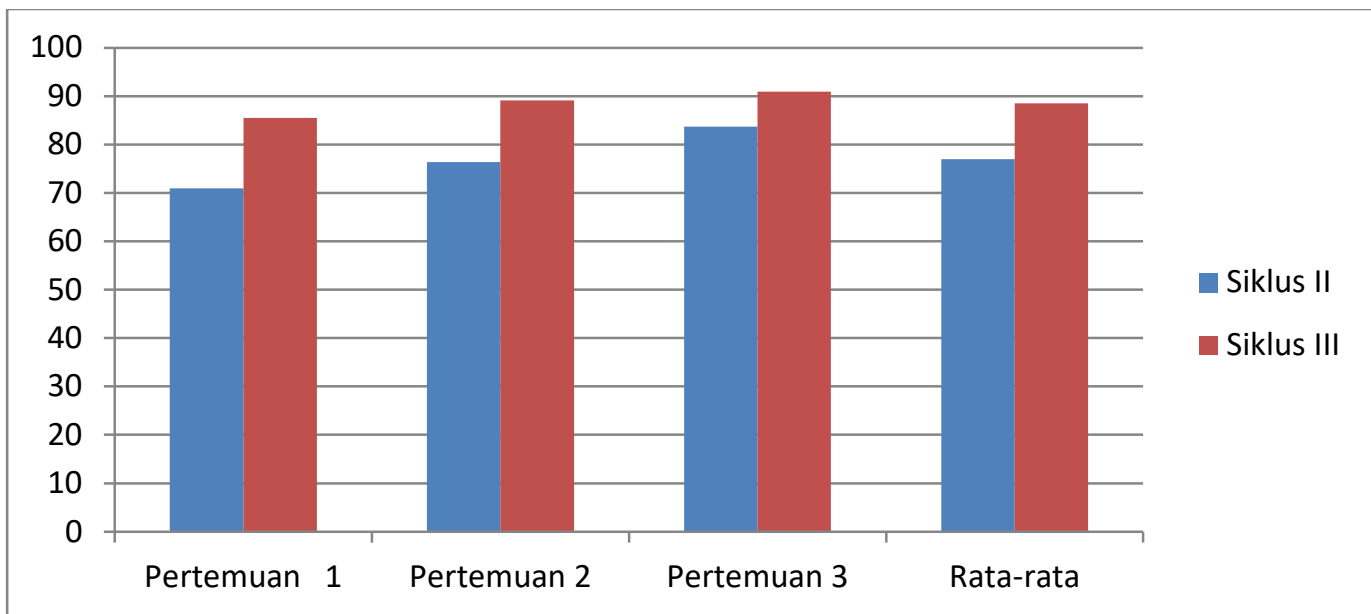

\section{Grafik 2: Perbandingan Peningkatan Kompetensi Guru dalam Merancang RPP antara Siklus 1 I dengan Siklus III}

Kompetensi guru yang terlihat pada Tabel 9 dan grafik 2 di atas sebagai berikut:

1. Merancang RPP berdasarkan silabus dan panduan BSNP mengalami peningkatan dari $80 \%$ menjadi $100 \%$, jadi peningkatannya sebesar $20 \%$ dengan prediket dari $\mathrm{B}$ ke $\mathrm{AB}$

2. Guru yang memahami dan menguasai komponen RPP dengan benar meningkat dari $93,33 \%$, menjadi $100 \%$, jadi peningkatannya sebesar $6,67 \%$ dengan prediket sudah $\mathrm{AB}$

3. Guru merumuskan identitas dengan lengkap, meningkat dari $100 \%$ menjadi $100 \%$, jadi meningkat sebesar $0 \%$ prdeiket sudah $\mathrm{AB}$

4. Guru mencantumkan alokasi waktu yang yang sesuai, siklus 1 rata-ratanya sebesar $100 \%$ menjadi $100 \%$, jadi meningkat sebesar $0 \%$, prediket sudah AB

5. Guru merumuskan tujuan pada RPP berdasarkan indikator yang ada pada silabus. dan memuat $\mathrm{ABCD}$, dari $66,67 \%$ meningkat menjadi 86,67 , jadi peningkatannya $20 \%$, atau dari prediket $\mathrm{C}$ menjadi $\mathrm{AB}$

6. Guru merumuskan materi ajar berdasarkan marei reguler, remidial dan pengayaaan, dari $66,67 \%$ menjadi $73,33 \%$, jadi peningkatannya $6,67 \%$, sementara prediket masih $\mathrm{C}$ ke $\mathrm{B}$ 
7. Guru memilih metode dan model pembelajaran yang tepat dan relevan, dari $60 \%$, menjadi $80 \%$, dengan peningkatan sebesar 20\%, Prediket dari C menajdi B.

8. Guru merumuskan langkah kegiatan pembelajaran sesuai dengan struktur yang lazim (kegiatan pendahuluan, kegiatan inti, kegiatan akhir)serta mengambarkan sintak model pembelajaran, dari $60 \%$ menjadi $73,33 \%$, dengan peningkatan sebesar 13,33\%, dari prediket C ke B.

9. Guru menetapkan alat, bahan dan sumber sesuai dengan tujuan atau kompetensi yang hendak dicapai siswa, dari $80 \%$ menjadi $100 \%$, terjadi peningkatan sebesar $20 \%$ dengan prediket dari B ke AB

10. Guru menyusun instrumen atau alat penilaian sesuai dengan tujuan dan indikator, dari $80 \%$ menjadi $80 \%$, dengan peningkatan $0 \%$ atau dari pediket B.

11. Guru merumuskan sumber belajar dengan benar. Dari $80 \% \%$ menjadi $80 \%$ dengan peningkatan $0 \%$ sementara prediket tetap B

Peningkatan kompetensi guru dari siklus II ke III dalam merancang RPP meningkat sebesar $11,22 \%$.

\section{KESIMPULAN, DAN SARAN}

\section{A. Kesimpulan}

Bimbingan berkala merupakan bantuan profesional pada guru yang menjalani kesulitan dalam pembelajaran. Adapun kebaikan bimbingan berkala tersebut adalah sebagai berikut :

1. Dapat dipakai memperbaiki guru-guru yang sangat lemah kinerjanya.

2. Perbaikan yang dilakukan sangat intensif, sebab masing-masing kelemahan ditangani satu per satu, sampai semua kelemahan menjadi berkurang atau hilang.

3. Proses memperbaiki kelemahan dilakukan secara mendalam, termasuk, guru merefleksi kemampuannya merencanakan pembelajaran.

4. Bagi guru-guru lain yang ingin tahu cara penyelesaian kelemahan-kelemahan guru yang dibimbing juga diperbolehkan ikut menjadi pendengar dalam pertemuan balikan.

Pada kegiatan bimbingan berkala ini peneliti fokus pada kegiatan membimbing mereka dalam menyusun RPP. Fungsi RPP adalah dapat mendorong guru lebih siap melakukan kegiatan pembelajaran dengan perencanaan yang matang. Oleh karena itu, setiap akan melakukan pembelajaran guru wajib memiliki persiapan, baik persiapan tertulis maupun tidak tertulis. Hal tersebut disampaikan oleh Nana Syaodih Sukmadinata (2006) bahwa :

"Perencanaan yang baik sangat membantu pelaksanaan pembelajaran, karena baik guru maupun peserta didik mengetahui dengan pasti tujuan yang ingin dicapai dan cara mencapainya, dengan demikian guru dapat mempertahankan situasi agar peserta didik dapat memusatkan perhatiannya pada pembelajaran yang telah diprogramkan".

Berdasarkan Tindakan yang telah peneliti lakukan didapat kesimpulan sebagai berikut :

1. Meningkatkan kemampuan guru dalam merencanakan, proses pembelajaran dapat dilakukan melalui bimbingan berkala oleh kepala sekolah;

2. Kualitas pembelajaran dari guru menjadi lebih baik, sehingga berpengaruh terhadap kualitas hasil belajar yang dicapai siswa. 
3. Terjalinnya hubungan kolegial antara kepala sekolah dengan guru dalam memecahkan masalah pembelajaran serta tugas-tugas profesinya.

Hasil yang dicapai dalam penelitian ini adalah terjadinya peningkatan kompetensi guru dalam merancang RPP dari siklus 1 ke siklus II sebesar 9,7\% dengan ratarata siklus 1 sebesar 67, 27. Pada siklus II sebesar 76, 97\%. Sedangkan pada siklus II ke siklus III terjadi peningkatan sebesar 11,22\% dengan rata-rata 88,48\%. Artinya penelitian ini mampu melebihi target atau indikator keberhasilan yang telah ditetapkan yaitu $85 \%$.

\section{B. Saran}

Berdasarkan Penelitian Tindakan Sekolah ini, adapun saran yang dapat penleiti berikan adalah sebagai berikut:

1. Kepala sekolah agar dapat melakukan pembinaan pada guru yang belum menyusun RPP.

2. Mengidentifikasi permasalahan-permasalahan yang timbul dalam merancang RPP.

3. Memotifasi kelengkapan RPP guru dalam menyukseskan implementasi KTSP.

4. Melaksanakan bimbingan terhadap guru dalam merancang RPP yang lebih baik

5. Melakukan teknik bimbingan berkala sesuai dengan permasalahan masingmasing dalam rangka memperbaiki RPP yang telah disusun.

\section{DAFTAR PUSTAKA}

Asma, Nur dkk. 2007. Silabus dan Hand Out Perencanaan Pengajaran. Padang: UNP.

Depdiknas. 2007. Pedoman Penyusunan Kurikulum Satuan Pendidikan di Sekolah Dasar. Jakarta: BSNP.

Lubis, Syahron. 2007. Modal Proses Pembelajaran Rayon. Padang: Universitas Negeri Padang.

Nana Syaodih Sukmadinata. 2006, Pengembangan Kurikulum: Teori dan Praktek. Bandung: Remaja Rosdakarya

Nana, Sudjana. 2008. Supervisi Akademik. Jakarta : Binamitra Publishing.

Pidarta, Made. 2009. Supervisi Pendidikan Kontekstual. Jakart : Rineka Cipta.

Sutjipto. 1993. Profesi Keguruan. Padang: Direktorat Jendral Pendidikan Tinggi.

Taufik. 2009. Merencanakan dan Melaksanakan Penelitian Tindakan Sekolah. LPMP Sumatera Barat.

Zulkarnaini. 2007. Perangkat Kurikulum dan Perangkat Pembelajaran Kurikulum Tingkat Satuan Pendidikan KTSP. LPMP Sumatera Barat: Depdiknas 